\title{
O EXERCÍCIO SOLIDÁRIO E SOCIAL DA EMPRESA ANTE AS RELAÇÕES DE TRABALHO NO BRASIL
}

Tiago Seixas Themudo*

Mônica de Sá Pinto Nogueira**

SUMÁRIO: Introdução; 2 Reflexos da atividade empresarial na bistória do direito do trabalbo sob a perspectiva dos direitos fundamentais sociais; 3 O exercício da atividade empresarial solidário e funcionalizado no mundo globalizado; 4 Os efeitos da atividade empresarial nas relações de trabalbo terceirizadas. Referências,

RESUMO: É objetivo deste trabalho investigar em que consiste a função solidária da empresa, e de que forma ela organiza as relações de trabalho de forma a efetivar os direitos e garantias fundamentais dentro do processo produtivo. Ao mesmo tempo, trata-se de analisar a noção de precarização do trabalho como consequência da não efetivação do exercício solidário da atividade empresarial. O direito do trabalho é produto do conflito entre o capital e o trabalho assalariado, cujo fundamento abrange um conjunto de fatores econômicos, sociais e políticos, que buscam equilibrar a utilização da força de trabalho livre e o sistema produtivo de bens e serviços. Entretanto, a Constituição Federal de 1988 inaugurou o Estado democrático de Direito, trazendo dentre seus objetivos a construção de uma sociedade livre, justa e solidária, indicando a importância do princípio da solidariedade social, que, por sua vez, passa a vincular o exercício da atividade empresarial. Além de que, a empresa passa a ser vista como uma organização de fatores de produção ou circulação de bens e serviços, que está inserida na ordem econômica como um agente organizador da atividade produtiva e gestora das propriedades privadas, além de ter dentre seus deveres o cumprimento da justiça social. Por conseguinte, a propriedade empresarial, corolário da propriedade privada e econômica, também teve o exercício condicionado ao cumprimento de sua função social. Desse modo, apesar de se beneficiar economicamente com a terceirização de sua cadeia produtiva, o exercício da atividade empresarial tem como novo limite jurídico para sua atuação a precarização das relações de trabalho. Para a elaboração do artigo, utilizou-se o método dedutivo para orientar uma pesquisa teórica, de caráter qualitativo.

\footnotetext{
"Doutor em Sociologia, professor do Programa de Pós-graduação em Direito Privado e Relações Sociais-UNI7, coordenador do grupo de pesquisa (CAPES) em Teorias do Desenvolvimento e Direito Privado, Brasil. E-mail: seixas@fa7.edu.br

"Bacharel em Direito (UNICHIRISTUS), mestranda do Programa de Pós-graduação em Direto Privado e Relações Sociais-UNI7, Brasil.
} 
PALAVRAS-CHAVE: Função solidária da empresa; Função social da empresa; Relações trabalhistas; Terceirização; Precarização das relações de trabalho.

\title{
THE SOLIDARY AND SOCIAL EXERCISE OF A COMPANY IN THE WAKE OF WORK RELATIONSHIPS IN BRAZIL
}

\begin{abstract}
Current paper investigates the company's solidary function and the manner it organizes labor relationships to concretize fundamental rights and guarantees within the productive process. An analysis will also be undertaken on the concept of labor precariousness as a product for the non-implementation of solidary exercise of the company's activity. Labor rights are the product of capital-labor struggle whose basis comprehends a set of economic, social and political factors that balances the use of free labor force and the productive system of goods and services. However, the 1988 Brazilian Constitution inaugurated the democratic state heralding the aims of a free, just and solidary society and indicates the importance of the principal of social solidarity. The latter links the exercise of entrepreneur's activities. The company is seen as an organization of production factors or the circulation of goods and services inserted within the economic order as an organizing agent of productive activity and manager of private property, with the addition of social justice. The exercise of entrepreneur property, a corollary of private and economic property, is conditioned to its social function. In spite of taking economic advantage with the outsourcing of the productive chain, the exercise of entrepreneur's activity involves labor precariousness as the new juridical limit. The deductive method has been employed for current qualitative theoretical research.
\end{abstract}

KEY WORDS: Firm 's solidary function; Firm 's social function; Labor relationships; Outsourcing; Poor labor relationships.

\section{EL EJERCICIO SOLIDARIO Y SOCIAL DE LA EMPRESA DELANTE DE LAS RELACIONES LABORALES EN BRASIL}

RESUMEN: Es objetivo de este estudio investigar en que consiste la función solidaria de la empresa, y de qué forma ella organiza las relaciones de trabajo de forma efectiva los derechos y garantías fundamentales dentro del proceso productivo. A la vez, se trata de analizar la noción de precarización del trabajo como consecuencia de la no efectividad del ejercicio solidario de la actividad empresarial. El derecho del trabajo es producto del conflicto entre el capital y el trabajo asalariado, cuyo fundamento abarca un conjunto de factores económicos, sociales y políticos, que buscan equilibrar la utilización de la fuerza de trabajo libre y el sistema productivo de bienes y servicios. Sin embargo, la Constitución Federal de 1988 inauguró el Estado democrático de Derecho, trayendo entre sus objetivos la construcción de una sociedad libre, justa y solidaria, indicando la importancia del principio de la solidaridad social, que, por su vez, pasa a vincular el ejercicio de la actividad 
empresarial. Además de que, la empresa pasa a ser vista como una organización de factores de producción o circulación de bienes y servicios, que está inserida en el orden económico como un agente organizador de la actividad productiva y gestora de las propiedades privadas, además de tener entre sus deberes el cumplimiento de la justicia social. Por consiguiente, la propiedad empresarial, corolario de la propiedad privada y económica, también tiene el ejercicio condicionado al cumplimiento de su función social. De ese modo, no obstante beneficiarse económicamente con la subcontratación de su cadena productiva, el ejercicio de la actividad empresarial tiene como nuevo límite jurídico para su actuación la precarización de las relaciones laborales. Para la elaboración del artículo, se utilizó el método deductivo para orientar una investigación teórica, de carácter cualitativo.

PALABRAS CLAVE: Función solidaria de la empresa; Función social de la empresa; Relaciones laborales; Tercerización; Precarización de las relaciones laborales.

\section{INTRODUÇÃO}

O Estado inaugurado pela Constituição da República Federativa do Brasil (CRFB), de 1988, rompeu com o passado, fazendo surgir um sistema político, jurídico, econômico e social que tem entre seus fundamentos, além da dignidade humana (art. $1^{\mathrm{o}}$, III, CF/88), os valores sociais do trabalho e a livre iniciativa (art. $1^{\mathrm{o}}, \mathrm{IV}, \mathrm{CF} / 88$ ), ao mesmo tempo em que prevê como objetivo a formação de uma sociedade justa, livre e solidária, bem como o desenvolvimento nacional (art. $3^{\circ}$, I e II, $\mathrm{CF} / 88)$.

Com efeito, esse mesmo sistema constitucional consagra como direito fundamental o direito de propriedade e a sua função social, que, até então, somente haviam sido previstos como princípios da ordem econômica do país, conforme previsão dos artigos $5^{\circ}$, incisos XXII e XXIII e 170, incisos II e III, ambos, da CF/88.

Isso significa que a propriedade adquiriu novo atributo, devendo servir, simultaneamente, como instrumento de realização individual e mecanismo para o exercício da atividade econômica. Desse modo, a definição do direito de propriedade como direito subjetivo e absoluto, com suporte apenas nos interesses do proprietário, não se justifica mais na atual ordem jurídica nacional, indicando que o direito à propriedade somente será garantido ante o exercício de sua função social.

É com essa noção de propriedade que se deve compreender a atividade empresarial, pois a propriedade é elemento essencial para a prática econômica 
organizada. O desenvolvimento da solidariedade empresarial é fator primordial para elevar a condição humana, tal significando expressar que a iniciativa privada tem o dever de contribuir para a efetivação dos direitos sociais da comunidade onde está inserida. Desse modo, a atividade empresarial tem seu exercício condicionado ao cumprimento de sua função solidária e social.

Nessa mesma perspectiva, a Constituição estabeleceu os direitos trabalhistas como direitos fundamentais (art. $7^{\circ}, \mathrm{CF} / 88$ ), cujo objetivo principal é a melhoria da condição social dos trabalhadores, e, concomitantemente, determinou que a ordem econômica é fundada na valorização do trabalho humano e na livre iniciativa, tendo como finalidade assegurar a todos uma existência digna, conforme os ditames da justiça social (art. 170, CF/88).

Ocorre que, em vez disso, os direitos e garantias fundamentais dos trabalhadores são reiteradamente relativizados, servindo como instrumento de enfrentamento das crises econômicas, que na realidade são cíclicas e acompanham a história do capital desde a sua gênese, significando que a cada nova recessão ocorrem mudanças com base no sacrifício da classe trabalhadora.

Designadamente, as empresas que possuem grande porte econômico, almejando a redução de custos, começaram a buscar organizações de pequeno porte superespecializadas e trabalhadores autônomos para terceirizar a produção de seus bens e serviços, dando ensejo a uma nova espécie de trabalho, em que o local de atividade do trabalhador não se restringe ao estabelecimento empresarial, indo bem além, porquanto ultrapassa as fronteiras nacionais.

A terceirização de etapas da cadeia produtiva (terceirização material ou externa) ocorre nas organizações mais modernas, havendo um deslocamento da atividade-fim da empresa, deixando, portanto, regra geral, de ter como objetivo a disponibilização de um produto ou de um serviço, passando meramente a constituir a gestão de uma marca.

Depara-se, então, um novo modelo de produção formado por organizações de acumulação flexível que tendem a privilegiar a desregulamentação das normas de proteção, descaracterizando a relação de trabalho, a qual, num contexto social e jurídico, se apoia na combinação dos cinco elementos fático-jurídicos constitutivos previstos nos arts. $2^{\circ}$ e $3^{\circ}$ da CLT - a prestação de trabalho por pessoa física a outrem, com pessoalidade, não eventualidade, onerosidade e subordinação.

Pretende-se, com efeito, demonstrar a seguir o quão é necessária a interação 
da empresa com seus empregados, implicando o exercício da atividade empresarial funcionalizada e solidária no âmbito das relações de trabalho como um todo. Em razão, no entanto, da necessidade de delimitação do tema, neste estudo, examinarse-á a atuação empresarial perante a segmentação das cadeias produtivas de trabalho.

Propõe-se, portanto, responder ao seguinte problema geral: - qual a relação entre a atividade empresarial e direito do trabalho? Secundariamente, se indaga: - em que consiste o exercício da atividade empresarial funcionalizada e solidária? Como e em que dimensão a atividade empresarial está vinculada à concretização dos direitos e garantias fundamentais sociais nas cadeias produtivas de trabalho?

Nesse âmbito, impende reafirmar que a força de trabalho não pode mais ser considerada como um simples fator de produção ou mecanismo operacional para produção e circulação de produtos e serviços em que o único intuito é obter lucro, haja vista que esta compreensão não parece mais ser apropriada perante as premissas estabelecidas pelos direitos e garantias fundamentais previstos na OIT, tampouco na Constituição Federal de 1988.

A empresa, expressão da propriedade e da economia, está submetida ao cumprimento das normas sociais, em especial as trabalhistas, relacionadas à segurança e saúde do trabalhador. Do contrário, não estará cumprindo a sua função social e, além do mais, a proteção jurídica social não diz respeito apenas aos interesses dos trabalhadores, mas também ao modelo de produção capitalista, o qual carece de padrões de concorrência, com limites mínimos de exploração do trabalho, para que não se torne autodestrutivo.

Então, pretende-se investigar em que consiste o exercício da atividade empresarial solidário e funcionalizado, quais os seus reflexos nas relações trabalhistas, e como e em que dimensão a atividade empresarial está vinculada à concretização dos direitos e garantias fundamentais sociais nas cadeias produtivas de trabalho. Para tanto, recorre-se ao método dedutivo para realizar demanda qualitativa e teórica.

No primeiro tópico, examinar-se-ão os reflexos da atividade empresarial nas relações de trabalho, cuja compreensão é essencial para se alcançar um equilíbrio entre as partes. A seguir, serão abordados os aspectos da atividade empresarial, abrangendo sua função solidária e social em busca de demonstrar sua vinculação ante as relações trabalhistas. Na última parte, será considerado o fenômeno da terceirização, com enfoque na natureza social do direito trabalhista, para propor como limite à atuação empresarial a precarização das relações de trabalho. 


\section{REFLEXOS DA ATIVIDADE EMPRESARIAL NA HISTÓRIA DO DIREITO DO TRABALHO SOB A PERSPECTIVA DOS DIREITOS FUNDAMENTAIS SOCIAIS}

O direito do trabalho é produto do conflito entre o capital e o trabalho assalariado, provocado, a princípio, pela Revolução Industrial ${ }^{03}$, cujo fundamento abrange um conjunto de fatores econômicos, sociais e políticos, que buscam equilibrar a utilização da força de trabalho livre e o sistema produtivo de bens e serviços $^{04}$.

O conjunto de princípios, regras e institutos trabalhistas compõe um valor finalístico essencial, que consiste na melhoria das condições de pactuação da força de trabalho na ordem socioeconômica, ou seja, segundo Maurício Godinho Delgado, "[...] o ramo justrabalhista realiza, na verdade, o fundamental intento democrático e inclusivo de desmercantilização da força de trabalho no sistema socioeconômico capitalista, restringindo o livre império das forças de mercado [... $]^{\prime 05}$.

Para esse autor, as normas do direito do trabalho estão circunscritas num movimento progressista e modernizante, do ponto de vista econômico e social, que tem como propósito a valorização do trabalho humano por meio da incrementação da gestão de pessoas no âmbito empresarial, que confere dinamismo e organicidade ao mercado econômico.

Decorre daí a função civilizatória e democrática do direito do trabalho, ensejando a preservação da dignidade do trabalhador, inserido em uma ordem econômica mundial, caracterizada, de um lado, pela concorrência predatória entre seus principais agentes econômicos e, de outro, pela eclosão de crises globais cíclicas desagregadoras.

A preocupação com o bem-estar dos trabalhadores deu ensejo à criação da Organização Internacional do Trabalho - OIT, em 1.919, por meio do tratado de Versalhes, contemplando-se, desde então, diversas declarações e tratados pluritemáticos, que dizem respeito ao sistema global de proteção dos direitos

\footnotetext{
${ }^{03}$ A Revolução Industrial ficou conhecida como o conjunto amplo de transformações econômicas e sociais que acompanharam o surgimento de avanços tecnológicos. Nesse período, houve uma migração, em grande escala, de camponeses, que deixaram suas terras e se transformaram em trabalhadores industriais, o que causou rápida expansão das áreas urbanas e introduziu outras formas de relacionamento (GIDDENS, Anthony. Sociologia. Trad. de Alexandra Figueiredo et al. 6. ed. Lisboa: Fundação Calouste Gulbenkian, 2005, p. 7).

${ }^{04}$ Os marcos no processo de formação e consolidação do Direito do Trabalho foram: Revolução Industrial (1.775); Revolução Francesa (1.789); Manifesto Comunista de Marx e Engels (1.848); Encíclica Rerum Novarum (1.891); Primeira Guerra Mundial e seus desdobramentos, como a formação da Organização Internacional do Trabalho - OIT (1.919) e a Constituição Alemã de Weimar (1.919); e a Constituição Mexicana (1.917).

${ }^{05}$ DELGADO, Maurício Godinho. Curso de Direito do Trabalho. 13. ed. São Paulo: LTr, 2014, p. 54-55.
} 
humanos, possibilitando o estabelecimento de limites legais à atividade empresarial para preservar o mínimo existencial à sobrevivência do empregado.

São mencionadas como exemplos a Declaração de Filadélfia (1948), que, já no seu preâmbulo, conclama por melhores condições de trabalho, haja vista existir grande número de pessoas que vivem em miséria e privações; a Declaração da OIT sobre os Princípios e Direitos Fundamentais do Trabalho (1988); e a Declaração sobre a Justiça Social para uma Globalização Equitativa (2.008), cuja finalidade é situar o pleno emprego produtivo e o trabalho decente como elemento central das políticas econômicas e sociais ${ }^{06}$.

Com o welfare state, os direitos de segunda dimensão ganharam contornos mais densos, de modo que a ordem jurídica internacional - com suporte no Pacto de Direitos Civis e Políticos (Pacto de San Jose da Costa Rica) e no Pacto de Direitos Econômicos Sociais e Culturais, ambos de 1966 - estabeleceu um rol de direitos, não apenas individuais, mas também sociais, de concretização necessária por parte do Estado em suas relações verticais, bem como pelos próprios particulares em suas vinculações privadas ${ }^{07}$.

Consoante Maurício Godinho Delgado e Gabriela Neves Delgado, "Além de ampliar os direitos de segunda dimensão, o Estado Social redefiniu o papel dos de primeira, concedendo-lhes certo cunho social como, $v . g$., ao vincular a propriedade privada à função social"08

.Entrementes, a ordem jurídica do Brasil, por meio da Constituição Federal de 1988, constituiu os direitos econômicos, sociais e culturais (artigos $1^{\circ}$, inciso III, $\mathrm{c} / \mathrm{c}$ artigo $5^{\circ}$ ao $9^{\circ}$, todos, da $\mathrm{CF} / 88$ ), ao lado dos direitos fundamentais individuais, qualificando-os como normas jurídicas de inegável conteúdo ético, que têm uma relação imbricada à ideia de dignidade da pessoa humana ${ }^{09}$ e de limitação do poder, positivadas no plano constitucional de determinado Estado democrático de Direito ${ }^{10}$,

\footnotetext{
${ }^{06}$ FABRE, Luiz (org.) Vade Mecum: direito internacional do trabalho. São Paulo: Orgânica, 2013, p. 492-505.

${ }^{07}$ MARMELSTEIN, George. Curso de direitos fundamentais. 5. ed. São Paulo: Atlas, 2014, p. 44-48.

${ }^{08}$ DELGADO, Maurício Godinho; DELGADO, Gabriela Neves. Constituição da República e Direitos Fundamentais: dignidade da pessoa humana, justiça social e direito do trabalho. 2. ed. São Paulo: LTr, 2013, p. 25.

${ }^{09}$ Para Ingo Wolfgang Sarlet, dignidade da pessoa humana é a qualidade intrínseca e distintiva de cada ser humano que o faz merecedor do mesmo respeito e consideração por parte do Estado e da comunidade, implicando, neste sentido, um complexo de direitos e deveres fundamentais que asseguram a pessoa tanto contra todos e qualquer ato de cunho degradante e desumano, como a lhe garantir as condições existenciais mínimas para uma vida saudável, além de propiciar e promover sua participação ativa e corresponsável nos destinos da própria existência e da vida em comunhão com os demais seres humanos. (SARLET, Ingo Wolfgang. Dignidade da pessoa humana e direitos fundamentais na Constituição Federal de 1988. 9. ed. rev. e atual. Porto Alegre: Livraria do Advogado, 2012, p. 58).

${ }^{10}$ MARMELSTEIN, George. Curso de direitos fundamentais. 5. ed. São Paulo: Atlas, 2014, p. 190-192.
} 
que, por sua importância valorativa, fundamentam e legitimam o ordenamento jurídico.

Surgem daí, com base na Declaração Universal dos Direitos Humanos de 1948 (DHDH) ${ }^{11}$, os direitos fundamentais trabalhistas, consubstanciando normas de proteção a serem observadas nas relações trabalhistas (arts. $7^{\circ}$ ao 11, CF/88), cujo objetivo principal é contemplar limites aos empregadores e direitos mínimos aos empregados ${ }^{12}$.

Maurício Godinho Delgado e Gabriela Neves Delgado concluem, expressando que a Constituição Federal inseriu em seu núcleo o direito do trabalho, propiciando-lhe dupla dimensão: os direitos e as garantias individuais e, ao mesmo tempo, os direitos sociais. Sob a perspectiva da pessoa humana, tais direitos servem de instrumento de concretização dos princípios, valores e regras constitucionais que dizem respeito à dignidade humana, à valorização do trabalho, à vinculação da propriedade a sua função social, efetivação da justiça social e democratização da sociedade civil. Na noção dos direitos sociais, o direito trabalhista compõe um conjunto de regras e princípios que traduzem efetivamente a realidade social, econômica, cultural, institucional e jurídica brasileiras ${ }^{13}$.

Em coerência com o exposto, por colaborar substancialmente com a eficácia dos direitos fundamentais trabalhistas, convém destacar a teoria da eficácia horizontal dos direitos fundamentais, reconhecida, expressamente, em 1958, quando o Tribunal Constitucional Federal alemão julgou o caso Luth, dando início ao desenvolvimento da ideia da dimensão objetiva dos direitos fundamentais e da eficácia irradiante desses direitos ${ }^{14}$.

Não somente o Estado tem o dever de buscar a completa dignidade do cidadão, nem mesmo apenas os pares devem obedecer tal preceito nos seus tratos privados, pois a pessoa humana, só pela sua condição de ser, detém o dever de atuar no sentido de ver satisfeita a sua dignidade. Isso porque a efetivação da

\footnotetext{
${ }^{11}$ Art. 23 da Declaração Universal dos Direitos Humanos de 1948. 1.Toda pessoa tem direito ao trabalho, à livre escolha de emprego, a condições justas e favoráveis de trabalho e à proteção contra o desemprego. 2. Toda pessoa, sem qualquer distinção, tem direito a igual remuneração por igual trabalho. 3. Toda pessoa que trabalhe tem direito a uma remuneração justa e satisfatória, que lhe assegure, assim como à sua família, uma existência compatível com a dignidade humana, e a que se acrescentarão, se necessário, outros meios de proteção social. 4. Toda pessoa tem direito a organizar sindicatos e neles ingressar para proteção de seus interesses. Disponível em: http://www.dhnet.org.br/direitos/deconu/textos/integra.htm\#23. Acesso em: 18 jun. 2017.

${ }^{12}$ MARMELSTEIN, George. Curso de direitos fundamentais. 5. ed. São Paulo: Atlas, 2014, p. 192-195.

${ }^{13}$ DELGADO, Maurício Godinho; DELGADO, Gabriela Neves. Constituição da República e Direitos Fundamentais: dignidade da pessoa humana, justiça social e direito do trabalho. 2. ed. São Paulo: LTr, 2013, p. 49-50.

${ }^{14}$ MARMELSTEIN, George. Curso de direitos fundamentais. 5. ed. São Paulo: Atlas, 2014, p. 339-340.
} 
dignidade da pessoa humana, classificada como centro do ordenamento jurídico brasileiro, privilegia o atendimento pleno de todos os direitos fundamentais do cidadão, dado que o feixe destes direitos, cluster rights $^{15}$, permite a ilação de que são interdependentes.

A recessão econômica mundial dos anos 1970/80 (crise do petróleo), entretanto, agravou as disparidades entre países industrializados e nações em desenvolvimento, no plano internacional, e entre distintos setores da sociedade, aspecto interno ${ }^{16}$. A crise abalou a rigidez do sistema econômico, acentuando, de um lado, a concorrência empresarial, e de outro, a taxa de desocupação no mercado de trabalho. Ademais, essa situação foi ainda agravada pelo processo de renovação tecnológica, considerando o fato de a eliminação das barreiras do tempo e do espaço haver fomentado a competição capitalista de modo global ${ }^{17}$.

Iniciou-se, nesse âmbito, um movimento de reestruturação das estratégias e modelos clássicos da gestão empresarial, favorecendo a repartição de competências interempresariais, dentre as quais se destaca a segmentação das cadeias produtivas de trabalho, que, regra geral, tem efeitos deletérios sobre as relações laborais.

De fato, logo após a inauguração da Constituição de 1988, manifestou-se no Brasil um movimento de desarticulação das normas trabalhistas, comprometendo a transição democrática do direito do trabalho. Isso porque a crise mundial, que despontou na Europa no final dos anos 1970, chegou a este país no decorrer dos anos de $1990^{18}$.

Não obstante, o conflito entre o binômio capital-trabalho, a atividade empresarial atualmente não pode mais se preocupar apenas com os lucros. Os fins da empresa, antes meramente individualistas e mercantis, com fundamento na noção de propriedade individual e absoluta, concebida pelo ideário liberal, tornamse coletivos, significando sua funcionalização.

\footnotetext{
${ }^{15}$ Tal expressão foi utilizada pela filósofa Judith Jarvis Thomson em seu livro intitulado de The Realm of Rights (1990, Harvard University Press), justamente para definir aqueles direitos que contêm outros direitos, a exemplo do que ocorre com os direitos fundamentais à vida, à liberdade e à propriedade. "Cluster rights", então, podem ser entendidos como todos direitos fundamentais que funcionam como agregados moleculares de valores existenciais. Em outras palavras, constituem um amplo feixe formado por outros direitos que guardam correlação com deveres subjetivos correspondentes. (Site Magistrado Trabalhista. Cluster Rights. Disponível em: http://www.magistradotrabalhista.com.br/2015/10/cluster-rights.html. Acesso em: 11 jul. 2017).

${ }^{16}$ TRINDADE, Antônio Augusto Cançado. Desafios e conquistas do Direito Internacional dos direitos humanos no início do século XXI. Disponível em: https:/www.oas.org/dil/esp/407-490\%20cancado\%20trindade\%20 OEA\%20CJI\%20\%20.def.pdf. Acesso em: 30 jun. 2017, p. 421.

${ }^{17}$ DELGADO, Maurício Godinho. Curso de Direito do Trabalho. 13. ed. São Paulo: LTr, 2014, p. 99.

${ }^{18}$ Ibidem, 2014, p. 117.
} 
A função social e solidária da empresa se relaciona com a ideia de que esta, juntamente com o Estado, também é responsável pelo bem-estar social, de maneira geral, com a preocupação trazida pelos efeitos da atividade empresarial à sociedade, e, de modo específico, por meio de seus trabalhadores, propiciando boas condições de trabalho e preocupando-se com seu bem-estar.

Consoante a ordem econômica, arrimada na livre iniciativa (art. 170, CF/88), as relações de trabalho no âmbito privado desenvolvem-se num contexto jurídico em que há desigualdade das partes, sendo o empregado hipossuficiente na relação jurídica trabalhista. E, por esse motivo, o trabalhador merece a proteção jurídica do Estado e da empresa, conforme leciona um dos mais importantes princípios do direito do trabalho, o da proteção ao trabalhador ${ }^{19}$.

Reafirma-se, então, a necessidade do exercício da função social e solidária da empresa em prol da concretização dos direitos e garantias fundamentais sociais nas relações de trabalho, pois, no direito pós-moderno, há necessidade da criação de mecanismos procedimentais apropriados para promover a realidade social.

Como bem explica Jorge Luiz Souto Maior, não se pode olvidar que o direito social tem como objetivo a formulação de critérios eficientes para impor limites necessários às relações capitalistas, visualizando a superação das injustiças sociais, portanto, a reivindicação de justiça social por intermédio do direito não aniquila a sua compreensão. Em vez disso, o desenvolvimento teórico do direito social confere a possibilidade de se estabelecerem diretrizes metodológicas para uma problematização da realidade que permitam vislumbrar uma solução jurídica para preservar e elevar a condição humana ${ }^{20}$.

\section{A ATIVIDADE EMPRESARIAL SOLIDÁRIA E FUNCIONALIZADA NO MUNDO GLOBALIZADO}

A empresa, no sentido econômico, pode ser definida como uma organização de fatores de produção ou circulação de bens e serviços, inserida na

${ }^{19}$ RODRIGUEZ, Américo Plá. Princípios de Direito do Trabalho. Tradução de Wagner D. Giglio. 3. ed. São Paulo: LTr, 2000, p. 36.

${ }^{20}$ MAIOR, Jorge Luiz Souto. Relação entre o Processo Civil e o Processo do Trabalho. In: Elisson Miessa (org.). O novo Código de Processo Civil e seus reflexos no processo do trabalho. Salvador: JusPodivm, 2015, p. 160. 
ordem econômica ${ }^{21}$ como agente organizador da atividade produtiva e gestora das propriedades privadas, além de ter, dentre seus deveres, o cumprimento da justiça social (art. 170, CF/88). Com efeito, a propriedade empresarial constitui elemento imprescindível para o modo de produção capitalista, representado pela conjugação entre o capital e a força física dos trabalhadores, que, por sua vez, trabalham na expectativa de constituir o próprio patrimônio.

A criação da propriedade empresária, entretanto, permitiu a concentração do poder econômico de tal maneira que promoveu enorme desigualdade social, dando ensejo ao desenvolvimento de instrumentos, cujo objetivo é coibir os abusos do poder econômico. Assim, ante o atual ordenamento jurídico, exige-se que as empresas desempenhem um papel além do que era outrora ideal, quando se vislumbrava unicamente o lucro, tendo em vista que a atividade destas atinge a sociedade numa perspectiva social tanto quanto a própria ordem econômica.

Evidencia-se, portanto, a imprescindibilidade da transição do direito empresarial, de um patamar eminentemente privado em direção a ideais voltados também ao coletivo, valorizando iniciativas sociais, educacionais e culturais, que agregam a comunidade como um todo.

A formação de um ambiente corporativo voltado também às contingências sociais ainda é bastante modesta, o que representa a urgência da conscientização empresarial para o fato de que a busca pelo lucro precisa ser relativizada perante a desigualdade social. Para tanto, o reconhecimento da função solidária e social da empresa é um ponto essencial.

Segundo Antônio Cançado Trindade, com a globalização da economia, as fronteiras dos países passaram a se abrir à livre circulação dos capitais, bens e serviços, sem, contudo, incluir socialmente os seres humanos. A concentração de renda e poder em escala mundial acompanha, pari passu, a globalização do mercado, acarretando "[...] o trágico aumento - estatisticamente comprovado dos marginalizados e excluídos em todas as partes do mundo, nesta mais recente manifestação de um perverso neodarwinismo social"².

Consoante Anthony Giddens, "as instituições modernas diferem de todas

\footnotetext{
${ }^{21}$ Segundo Max Weber, a ordem econômica é a distribuição do efetivo poder de disposição sobre bens e serviços econômicos, que resulta consensualmente do modo de equilíbrio de interesses e da maneira como a ordem jurídica e a economia social são de fato empregados (WEBER, Max. Economia e sociedade. Brasília: UnB, 2012, v. I, p. 209).

${ }^{22}$ TRINDADE, Antônio Augusto Cançado. Desafios e conquistas do direito internacional dos direitos humanos no início do século XXI. Disponível em: https://www.oas.org/dil/esp/407-490\%20cancado\%20trindade\%20 OEA\%20CJI\%20\%20.def.pdf. Acesso em: 30 jun. 2017, p. 421.
} 
as formas anteriores de ordem social quanto ao seu dinamismo, ao grau em que interferem com hábitos e costumes tradicionais, e a seu impacto global", sugerindo que a Modernidade tem que ser compreendida num nível institucional. Isso porque as transformações introduzidas pelas instituições modernas se imiscuem no modo de vida individual, aproximando as influências globalizantes e as disposições pessoais. ${ }^{23}$

Para esse autor, a Modernidade é uma cultura do risco, no sentido de que introduz parâmetros pouco conhecidos ou inteiramente desconhecidos das gerações anteriores, como, e.g., mecanismos econômicos globais, fazendo surgir questões morais que a Modernidade exclui institucionalmente.

Desse modo, a Modernidade pode ser entendida em duas dimensões. A primeira é equivalente ao mundo industrializado - relações sociais implicadas no uso generalizado da força material e do maquinário nos processos de produção. E a segunda configura o capitalismo - sistema de produção de mercadorias, que envolve mercados competitivos de produtos e a mercantilização da força de trabalho ${ }^{24}$.

Outrossim, Gilberto Bercovici sustenta que o Estado deve agir para beneficiar todas as classes, assegurando, portanto, "[...] que o máximo desenvolvimento do trabalho seja o pressuposto da máxima aquisição de capital, instituindo a possibilidade de aquisição de capital (e, consequentemente, de educação e dignidade) pelos trabalhadores" ${ }^{25}$.

Marilza Geraldo do Nascimento reitera a ideia de que o sentido do trabalho na realidade contemporânea não se limita à sua concepção econômica, encerrando outro significado, próprio de uma sociedade solidária "[...] sociedade em que a exclusão é concebida como desvio, que exige correção pelos seus próprios membros e instituições"26.

Ademais, a preocupação com a solidariedade social não é recente. De acordo com Anthony Giddens, Émile Durkheim já defendia, em 1893, no livro $A$ Divisão Social do Trabalbo, que o advento da era industrial requisitava dois tipos de solidariedade - mecânica e orgânica - as quais foram relacionadas, pelo autor, respectivamente, à divisão do trabalho e ao crescimento entre ocupações diferentes. ${ }^{27}$

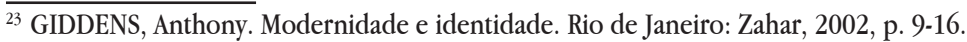

${ }^{24}$ Ibidem, 2002, p. 21.

${ }^{25}$ BERCOVICI, Gilberto. Soberania e Constituição: para uma crítica do constitucionalismo. São Paulo: Quartier Latin, 2008, p. 207.

${ }^{26}$ NASCIMENTO, Marilza Geralda do. O trabalho como valor: afirmação e crise em perspectiva tridimensional. Dissertação de mestrado. Faculdade de Direito. Universidade Federal de Minas Gerais, 2002, p. 219.

${ }^{27}$ GIDDENS, Anthony. Sociologia. Trad. de Alexandra Figueiredo et al. 6. ed. Lisboa: Fundação Calouste Gulbenkian, 2005, p. 9.
} 
Sobretudo, porém, em decorrência dos efeitos catastróficos causados pela Segunda Guerra Mundial, acentuou-se um sentimento de solidariedade internacional, consubstanciando direitos diretamente relacionados com a dignidade humana, denominados por Karel Vasak como direitos de terceira geração. De fato, esses direitos emergem fundados na máxima da fraternidade e solidariedade universais ${ }^{28}$.

É justamente nesse contexto que a Constituição Federal de 1988 inaugurou o Estado democrático de Direito, trazendo dentre seus objetivos a formação de uma sociedade livre, justa e solidária (art. $3^{\circ}$, I, CF/88), indicando a importância do princípio da solidariedade social, que, por sua vez, passa a ocupar lugar de destaque na ordem econômica do país.

De acordo com a compreensão de Eros Graus, a sociedade livre é a que realiza a liberdade em todas as suas manifestações, sobretudo, como liberdade real, da qual são igualmente titulares a pessoa e a coletividade; a sociedade justa é aquela que concretiza a justiça social, a qual consiste na superação das injustiças na repartição do produto econômico; e a sociedade solidária é que não inimiza os homens entre $\mathrm{si}^{29}$.

Seguindo esse mesmo raciocínio, Gilberto Bercovici proclama a noção de que o objetivo do Estado é instituir uma república com interesses recíprocos, garantindo, assim, a solidariedade dos preceitos sociais, cuja finalidade principal é a eliminação da inimizade entre capital e trabalho. Citando Lorenz von Stein, o autor propõe o estabelecimento de interesses solidários, e não a abolição do capital ou a submissão deste ao trabalho ${ }^{30}$.

Por todas essas razões, o princípio da solidariedade transmuda-se num princípio jurídico, incidindo sobre toda a ordem jurídica, conformando e condicionando o exercício da atividade econômica, a qual abrange a atuação empresarial. A ideia de solidariedade empresarial confere exigibilidade, constituindose como fonte de obrigações positivas e negativas, além de servir como critério imperativo de outras normas ${ }^{31}$.

Nesse intento, a Constituição Federal de 1988 também consagrou como

\footnotetext{
$\overline{{ }^{28} \text { BONAVIDES, Paulo. }}$ Curso de Direito Constitucional. 31. ed. São Paulo: Malheiros, 2016, p. 583-585.

${ }^{29}$ GRAU, Eros Roberto. A ordem econômica na Constituição de 1988. 17. ed. São Paulo: Malheiros, 2015, p. 212.

${ }^{30}$ BERCOVICI, Gilberto. Soberania e Constituição: para uma crítica do constitucionalismo. São Paulo: Quartier Latin, 2008, p. 207.

${ }^{31}$ MATIAS, João Luís Nogueira. A ordem econômica e o princípio da solidariedade na Constituição Federal de 1988. Disponível em: http://www.periodicos.ufc.br/nomos/article/view/6414. Acesso em: 23 jun. 2017.
} 
fundamentais o direito à propriedade e a sua função social, restando a garantia deste condicionada ao cumprimento do exercício de sua função social, haja vista o fato de este direito ser pressuposto para a garantia da inviolabilidade à vida, à liberdade, à igualdade e à segurança, implicando alteração do próprio conteúdo do direito de propriedade pela imposição da função social da propriedade (art. $5^{\circ}$, incisos XXII e XXIII, da CF/88).

O Texto Constitucional estabeleceu no seu artigo 170, incisos II e III, o direito de propriedade privada e sua função social como princípios da ordem econômica, consubstanciando, segundo Eros Grau, "diretrizes (Dworkin) - normas-objetivo - dotadas de caráter constitucional conformador"32, razão pela qual a garantia constitucional da propriedade inexiste se não for cumprida sua função social. Como bem explicam Gustavo Tepedino e Anderson Schreiber, "A postura, refletida nestes dispositivos e em outras passagens do texto constitucional, conduz inevitavelmente à conclusão de que, no direito brasileiro, a garantia da propriedade não pode ser compreendida sem atenção a sua função social"33.

Ademais disso, foram inseridos na Constituição outros dispositivos, cujo núcleo do conteúdo diz respeito à função social da propriedade, como, exempli gratia, os artigos 182 e 183, disciplinando a utilização da propriedade urbana, e os artigos 184 e 185, que regulam o uso da propriedade rural. De fato, a utilização da propriedade urbana foi condicionada ao cumprimento de sua função social, devendo observar, portanto, as exigências fundamentais da ordenação da cidade de acordo com o seu plano diretor, contribuindo para os princípios gerais da dignidade humana e do trabalho, dentre outros.

A Constituição, igualmente, impôs o exercício da função social à propriedade rural, considerando critérios como o aproveitamento racional e utilização adequada da propriedade, além do dever de observância da legislação trabalhista concernente ao bem-estar dos trabalhadores (art. 186, CF/88). Infere-se, assim, que na Constituição existem diversas normas acerca da regularização do uso da propriedade, estando sempre implícita ou explícita a obrigatoriedade do exercício de sua função social. Expresso de outro modo, existem diversas situações proprietárias, as quais podem ser identificadas de acordo com a destinação da propriedade - rural ou urbana -

\footnotetext{
${ }^{32}$ GRAU, Eros Roberto. A ordem econômica na Constituição de 1988. 17. ed. São Paulo: Malheiros, 2015, p. 232. (Grifos originais).

33 TEPEDINO, Gustavo; SCHREIBER, Anderson. A garantia da propriedade no Direito Brasileiro. Revista da Faculdade de Direito de Campos, ano VI, n. 6, pp. 101-119, jun./2005, p. 102.
} 
bem como segundo sua natureza econômica - produtiva ou improdutiva - o que indica a propriedade não se reduzir apenas ao estatuto jurídico ${ }^{34}$.

Em síntese, observa-se que a propriedade deixou de ser um direito absoluto, pois o exercício de sua função social é imanente ao seu fundamento, bem como à sua razão e justificação. A concepção moderna de propriedade condiciona o direito de propriedade a interesses que não dizem respeito exclusivamente à propriedade individual, mas sim aos preceitos da coletividade. São exemplos a proteção ao meio ambiente e as relações de trabalho decorrentes da situação proprietária ${ }^{35}$.

A propriedade e sua função social conformam direitos constitucionalmente constituídos, perfazendo um conjunto de princípios e regras de acesso e de exclusão, que têm como objetivo assegurar o exercício de tais direitos, consoante entendimento de Stephen Holmes e Cass R. Sunstein: La propiedad es una relación social legalmente construida, un conjunto de regla de acesso y de exclusión cercadas por los poderes legislativo y judicial y dotada de protección judicial $[\ldots]^{\prime 36}$.

É assim que a propriedade assume o dever da promoção social, na percepção de que as suas diversas modalidades e interpretações devem garantir e promover os valores sobre os quais se fundamenta o ordenamento jurídico, resultando numa concepção moderna de propriedade, que constitui várias instituições correlacionadas aos diversos tipos de bens e de titulares, implicando distintos tipos de propriedade, cada qual com aspectos próprios ${ }^{37}$.

Como não poderia deixar de ser, a propriedade empresarial, corolário da propriedade privada e econômica, também teve o exercício condicionado ao cumprimento de sua função social, consoante aduz Caio Mário da Silva Pereira: "Obviamente o direito de propriedade, especialmente quando reveste a forma empresária, deve suportar restrições peculiares com que se conformará, de acordo com as exigências do bem comum, e sujeitar-se-á a obrigações que a limitem, de

${ }_{34}$ TEPEDINO, Gustavo. Comentários ao Código Civil: direito das coisas. Antônio Junqueira de Azevedo (coord.), São Paulo: Saraiva, 2011, v. 14, p. 238.

${ }^{35}$ BERCOVICI, Gilberto. Constituição econômica e desenvolvimento: uma leitura a partir da Constituição de 1988. São Paulo: Malheiros, 2005, p. 147.

${ }^{36}$ HOLMES, Stephen; SUNSTEIN, Cass R. El costo de los derechos: por qué la libertad depende de los impuestos. Trad. de Stella Mastrangelo. Buenos Aires: Siglo veintiuno, 2011, p. 81. Tradução livre: "A propriedade é uma relação social legalmente constituída, um conjunto de regras de acesso e exclusão cercadas pelos poderes legislativo e judicial e dotada de proteção judicial".

${ }^{37}$ SILVA, José Afonso da. Direito urbanístico brasileiro. 7. ed. São Paulo: Malheiros, 2015, p. 73. 
molde a reprimir a sua utilização abusiva" ${ }^{"}$.

A limitação constitucional que condiciona o direito de propriedade ao exercício de sua função social reflete diretamente sobre a propriedade empresarial, impondo-lhe também o dever de cumprimento de uma função social correspondente ${ }^{39}$. Nesse sentido, Gilberto Bercovici, citando Karl Renner, suscita que a funcionalização da propriedade acompanha as mudanças nas relações produtivas, tornando-se fundamento do regime jurídico do instituto da propriedade, de seu reconhecimento e da sua garantia, implicando o seu conteúdo ${ }^{40}$.

Para esse autor, entretanto, embora a função social aparente ter conotação socialista, diz respeito diretamente ao regime capitalista, cuja finalidade é legitimar o lucro e a propriedade privada dos bens de produção, passando, portanto, a integrar o conceito de propriedade, justificando-a e legitimando-a. Com efeito, a Constituição, além de ordenar as limitações, obrigações e onerar relativamente a propriedade privada, adota um princípio de transformação da propriedade capitalista, sem, contudo, socializá-la ${ }^{41}$.

Assim sendo, a propriedade como princípio fundamental econômico, além de condicionar seu exercício de uso, gozo e disposição, compele o proprietário a exercitar determinadas faculdades, significando que da função social da empresa decorrem deveres e obrigações no exercício das atividades organizacionais, os quais condicionam a atuação empresarial. Cumpre observar, porém, que a função social da propriedade não se limita às restrições de uso e gozo que lhe são impostas ${ }^{42}$.

Fábio Konder Comparato explica que as restrições ao uso e gozo dos bens próprios são meramente limites negativos aos direitos do proprietário. A função social da empresa é o poder de dar ao objeto da propriedade destino determinado, de vinculá-lo ao interesse coletivo e não ao interesse próprio do dominus, mas "[...] se se está diante de um interesse coletivo, essa função social da propriedade corresponde a um poder-dever do proprietário, sancionável pela ordem jurídica” ${ }^{\text {”3 }}$.

Acresça-se, por fim, que a função social da empresa também é reconhecida

\footnotetext{
${ }^{38}$ PEREIRA, Caio Mário da Silva. Instituições de Direito Civil. Direitos reais. Atual. por MONTEIRO FILHO, Carlos Edison do Rêgo. 10. ed. Rio de Janeiro: Forense, 2005, v. IV, pp. 106-107.

${ }^{39}$ REQUIÃO, Rubens. A co-gestão: a função social da empresa e o Estado de Direito. Revista Forense, São Paulo, a. 74 , v. 262 , pp. 31-39, abr.-jun./1978, p. 32 .

${ }^{40}$ BERCOVICI, Gilberto. Constituição econômica e desenvolvimento: uma leitura a partir da Constituição de 1988. São Paulo: Malheiros, 2005, p. 145-147.

${ }^{41}$ BERCOVICI, Gilberto. Constituição econômica e desenvolvimento: uma leitura a partir da Constituição de 1988. São Paulo: Malheiros, 2005, p. 145-147.

${ }^{42}$ SILVA, José Afonso da. Direito Urbanístico brasileiro. 7. ed. São Paulo: Malheiros, 2015, p.74.

${ }^{43}$ COMPARATO, Fábio Konder. Direito Empresarial. Estudos e pareceres. São Paulo: Saraiva, 1995, p. 75.
} 
no ordenamento jurídico brasileiro, na lei n. $6.404 / 76^{44}$, lei $11.101 / 05^{45}$ e no Código Civil, no sentido de condicionar o exercício da propriedade às finalidades econômicas e sociais, trazendo ainda outras limitações relacionadas, como, v.g., , a atuação efetiva do Estado no sentido de que as áreas socialmente improdutivas sejam destinadas à produção (art. 1228, $\S 1^{\circ}$, do CC/2002).

Como explica Gustavo Tepedino, ao tecer comentários sobre o art. 1.228, $\S 1^{\circ}$, do CC/2002, "[...] a função social propriedade [...] vincula o exercício do direito de propriedade às suas finalidades econômicas e sociais, de modo a consagrar a função social como categoria genuinamente jurídica, isto é, como aspecto interno redefinidor do núcleo de poderes do proprietário" ${ }^{\text {. }}$.

A ordem econômica considera a propriedade e sua função social como elementos que se inserem no processo de bens de produção, impelindo à proporcionalidade entre os interesses do proprietário e os da coletividade ${ }^{47}$. Mais do que isso, o exercício da atividade empresarial é limitado por seu dever de solidariedade e por sua função social, com o objetivo da realização de uma conduta que atenda aos interesses comuns do país, dentre os quais se destacam os direitos fundamentais trabalhistas. Assim, a atuação empresarial deve alcançar o desenvolvimento de políticas sustentáveis que concorram para a concretização da dignidade humana do trabalhador, conforme se demonstrará em seguida, no âmbito das relações de trabalho terceirizadas.

\section{OS EFEITOS DA ATIVIDADE EMPRESARIAL NAS RELAÇÕES DE TRABALHO TERCEIRIZADAS}

Por outro lado, em decorrência do desgaste do modelo fordista tradicional, ganhou dimensão o fenômeno da descentralização produtiva, denominado

\footnotetext{
${ }^{44}$ Art. 116, P.U. Lei 6.404/76. O acionista controlador deve usar o poder com o fim de fazer a companhia realizar o seu objeto e cumprir sua função social, e tem deveres e responsabilidades para com os demais acionistas da empresa, os que nela trabalham e para com a comunidade em que atua, cujos direitos e interesses deve lealmente respeitar e atender. Art. 154, caput, Lei 6.404/76. O administrador deve exercer as atribuiçóes que a lei e o estatuto lhe conferem para lograr os fins e no interesse da companhia, satisfeitas as exigências do bem público e da função social da empresa.

${ }^{45}$ Art. 47, Lei 11. 101/05. A recuperação judicial tem por objetivo viabilizar a superação da situação de crise econômico-financeira do devedor, a fim de permitir a manutenção da fonte produtora, do emprego dos trabalhadores e dos interesses dos credores, promovendo, assim, a preservação da empresa, sua função social e o estímulo à atividade econômica.

${ }^{46}$ TEPEDINO, Gustavo. Comentários ao Código Civil: direito das coisas. Antônio Junqueira de Azevedo (coord.), São Paulo: Saraiva, 2011, v. 14, pp. 235-236.

${ }^{47}$ GRAU, Eros Roberto. A ordem econômica na Constituição de 1988. 17. ed. São Paulo: Malheiros, 2015, p. 232.
} 
terceirização ou outsourcing. A produção em larga escala padronizada foi marcada pela insuscetibilidade de adaptação para atender a demanda dos consumidores, razão pela qual cedeu lugar aos modelos de acumulação flexível (toyotismo) ${ }^{48}$.

A produção de bens e serviços terceirizados foi criada pela área de administração de empresas, com o objetivo de fomentar a descentralização produtiva por meio de organizações prestadoras de serviços. O deslocamento das atividades periféricas para outras empresas especializadas resultou na externalização dos seus custos de produção, possibilitando que as empresas se concentrassem apenas em sua atividade principal, otimizando seus lucros ${ }^{49}$.

A produção de bens e serviços foi reestruturada, mudando do modo vertical para o horizontal, passando a envolver três partes, a saber: a empresa tomadora de serviços - que recebe a prestação de labor, mas não assume a posição clássica de empregadora; o trabalhador - prestador dos serviços, que realiza as atividades materiais e intelectuais junto à empresa tomadora de serviços; e a empresa terceirizante, que contrata o trabalhador, firmando com ele os vínculos jurídicos trabalhistas ${ }^{50}$.

Com efeito, a terceirização consiste na transferência de alguns serviços ou etapas da produção de uma empresa para outra, em caráter continuado, mediante um contrato de natureza civil ${ }^{51}$. Implica, portanto, a dissociação do vínculo econômico em relação ao de teor jurídico nas ligações de trabalho, provocando um trato trilateral em face da contratação de força de trabalho no mercado capitalista ${ }^{52}$.

A realidade mundial de alta competitividade influenciou o crescimento do mercado da terceirização, concebendo outros modelos. Esse modo de produção foi dividido em espécies, criando dois grandes grupos - a terceirização interna, que traz para a empresa trabalhadores alheios; e a terceirização externa, que, por sua vez, leva para o exterior da empresa as etapas de seu ciclo produtivo ${ }^{53}$.

Marcos Túlio Viana explica a diferenciação entre as duas espécies de terceirização, fazendo uma comparação com o trabalho por conta própria e aquele

\footnotetext{
${ }^{48}$ HARVEY, David. Condição pós-moderna. Tradução de Adail Ubirajara Sobral e Maria Stela Gonçalves. 25. ed. São Paulo: Loyola, 2014, p.140.

${ }^{49}$ DELGADO, Maurício Godinho. Curso de Direito do Trabalho. 13. ed. São Paulo: Ltr, 2014, p. 452.

${ }^{50}$ Ibidem, 2014, p. 452.

${ }^{51}$ LIMA, Francisco Meton Marques de. Elementos de Direito do Trabalho e processo do trabalho. 14. ed. São Paulo: LTr, 2013, p. 132.

${ }^{52}$ LIMA, Francisco Meton Marques de. Elementos de Direito do Trabalho e processo do trabalho. 14. ed. São Paulo: LTr, 2013, p. 132.

${ }^{53}$ VIANA, Márcio Túlio. A terceirização revisitada: algumas críticas e sugestões para um novo tratamento da matéria. Revista TST, v. 78, n. 4, pp. 198-224, out./dez., 2012, p. 200.
} 
por conta alheia. Por um lado, a terceirização interna assemelha-se ao trabalho por conta alheia, pois desloca o empregado para fora da relação jurídica de emprego, conforme dita: "[...] uma empresa se serve dos empregados contratados por outra, e o que lhe interessa, diretamente, é a própria prestação de serviços. Assim, à medida que o produto é construído, vai passando automaticamente para suas mãos”. De outra parte, a terceirização externa mais se aproxima do conceito de trabalho por conta própria, "Uma empresa contrata a outra, mas o que lhe interessa é o produto final. Por isso, só ao término da produção passa a ter propriedade sobre ele" ${ }^{n 4}$.

No atual modelo de acumulação flexível, há a fragmentação da unidade de trabalhadores, pois o sistema de produção deixa de ser concentrado em um mesmo ambiente, tal como os modelos denominados: outsourcing, terceirização de etapas da cadeia produtiva, e o offshoring, que consiste em fábricas em todo o globo.

Como se vê, a terceirização não ocorre somente entre organizações de um país, existindo empresas que atuam em um determinado Estado e contratam terceirizadas em outro. Essa espécie de terceirização, denominada offshoring, consiste na terceirização da produção ou de etapas da cadeia produtiva em variadas nações, ou seja, as próprias etapas produtivas são subcontratadas, Há, portanto, o deslocamento da própria atividade-fim da empresa, significando que o exercício empresarial passa a consistir numa combinação de fatores diversos de produção, portanto, se aproxima bem mais de um modo de administração de marcas do que de uma ação empresarial, uma vez que sua cadeia produtiva é totalmente segmentada.

Como bem explica Fernando Hugo R. Miranda, as empresas de grande porte estão pulverizadas em longas cadeias de produção sem unidade de interesses e coordenação, consubstanciando processos sucessivos de externalização das etapas produtivas. Assim, há interferência no direito do trabalho, criando o risco de que o fracionamento das cadeias de produção, "[...] chegue a tal limite que o empregador deixe de existir, praticamente desaparecendo à luz do dia. É o que se passou a denominar de empregador desmaterializado - de-materialized employer" ${ }^{\prime \prime}$.

É justamente nessa direção que David Weil, em sua obra Fissured workplace ou splitting-off' (Local de trabalho fissurado ou dividido), citado por Raphael Miziara e Roberto Wanderley Braga, acrescenta que "[...] as grandes corporações têm se

\footnotetext{
${ }^{54}$ VIANA, Márcio Túlio. A terceirização revisitada: algumas críticas e sugestões para um novo tratamento da matéria. Revista TST, v. 78, n. 4, pp. 198-224, out./dez., 2012, pp. 200-201.

${ }^{55}$ MIRANDA, Fernando Hugo R. A questão das cadeias produtivas no âmbito do direito do trabalho e os limites da racionalidade da súmula n. 331/TST. Revista LTr, São Paulo: LTr, v. 80, n. 12, p. 1470-1481, dez./2016.
} 
esquivado de seu papel como empregadores diretos por meio da terceirização de trabalho para pequenas empresas que, por sua vez, competem ferozmente entre si." Prosseguindo, o autor ressalta como resultado inevitável da terceirização, dentre outros, as péssimas condições de saúde e de segurança, bem como a desigualdade de renda ${ }^{56}$.

Corrobora esse entendimento Márcio Túlio Viana, ao enunciar a ideia de que, na terceirização externa, a empresa descarta etapas de seu ciclo produtivo e seus respectivos trabalhadores, transformando-se numa fábrica vazia, ou seja, se faz mera gerenciadora de rede, sem máquinas nem operários, hipótese em que a terceirização desliza para a terciarização $0^{57}$.

Para o autor, no limite, a mesma razão que faz a empresa "enxugar" "[...] a impele a se desgarrar do território de origem, como se passasse de imóvel a móvel, sempre em busca de mão-de-obra barata, direitos flexíveis, sindicatos dóceis e políticas fiscais favoráveis" 58 .

Com efeito, o fenômeno da terceirização externa provoca o distanciamento do espaço-tempo, movimento inerente à sociedade moderna, que, segundo Anthony Giddens, desenvolve uma dimensão vazia de tempo. O sistema de tempo universal e as zonas de tempo globalmente padronizadas são utilizados pelas empresas de grande porte, ao terceirizarem suas cadeias produtivas de trabalhos nos diversos países $^{59}$.

De acordo com esse sociólogo, muitas são as modalidades de "tempo vivido" em situações estruturadas pela separação tempo-espaço, contudo, as organizações sociais são inconcebíveis sem a reintegração do tempo e do espaço. A organização social moderna supõe possível a coordenação das ações de seres humanos fisicamente distantes, o que implica "desencaixe das instituições sociais" ${ }^{\prime 0}$.

Daí, parece acertado concluir que toda e qualquer terceirização, em alguma escala, acarreta precarização nas relações de trabalho. O propósito da terceirização, entretanto, não é a precarização dos direitos sociais, uma vez que atingiria

\footnotetext{
${ }^{56}$ MIZIARA, Raphael; BRAGA, Roberto Wanderley. Informativos do TST: comentados e organizados por assunto. 2. ed. Salvador: JusPodivm, 2017, p. 268.

${ }^{57}$ VIANA, Márcio Túlio. As várias faces da terceirização. Revista Fac. Direito UFMG, Belo Horizonte, n. 54, p. 141156, jan./jun. 2009, p. 141.

${ }^{58}$ VIANA, Márcio Túlio. A proteção social do trabalhador no mundo globalizado: o Direito do Trabalho no limiar do século XXI. Revista Fac. Direito UFMG, Belo Horizonte, p. 153-186, Disponível em: https://www.direito. ufmg.br/revista/index.php/revista/article/viewFile/1145/1078. Acesso em: 15 jul. 2017.

${ }^{59}$ GIDDENS, Anthony. Modernidade e identidade. Rio de Janeiro: Zahar, 2002, p. 22-23.

${ }^{60}$ Idem.
} 
diretamente princípios inerentes ao Estado democrático de Direito, como, verbi gratia, a dignidade da pessoa humana e o valor social do trabalho. Não devem ser aceitos, então, os efeitos deletérios da terceirização nas relações trabalhistas, ou seja, as repercussões perniciosas circunstanciais às relações de trabalho provocadas pela terceirização, uma vez que não faz parte da lógica intrínseca da relação de trabalho ${ }^{61}$. Suscita-se, por conseguinte, a noção de que o exercício da atividade empresarial deve ser limitado pela precarização das relações de trabalho, razão pela qual as situações que envolvem a terceirização de etapas da cadeia produtiva hão de ser analisadas em cada caso concreto. Assim, há de se avaliar individualmente se a terceirização acarreta repercussões nocivas circunstanciais ou não às relações de trabalho.

Tal situação é contemplada pela Constituição Federal do Brasil de 1988, a qual contingencia, por meio do seu conjunto normativo ${ }^{62}$, "[...] fórmulas surgidas na economia e na sociedade de exercício de poder sobre as pessoas humanas e de utilização de sua potencialidade laborativa". Os princípios e regras constitucionais impõem divisa intransponível para a prática empresarial terceirizante, delimitando esse processo disruptivo a situações manifestamente determinadas, não sendo, portanto, possível a terceirização das cadeias produtivas de trabalho que ultrapassem o limite constitucional ${ }^{63}$.

De fato, a realidade da terceirização das cadeias produtivas de trabalho no mundo capitalista contemporâneo tende a flexibilização e desregulamentação das normas jurídicas trabalhistas, desestabilizando a identidade individual e social do trabalhador.

\section{CONCLUSÃO}

O direito do trabalho é fruto do capitalismo, considerando-se, especialmente, a dinâmica econômica deflagrada após a Revolução Industrial, que ensejou a regulamentação das condutas, interesses, relações e instituições decorrentes do conflito entre o capital e o trabalho.

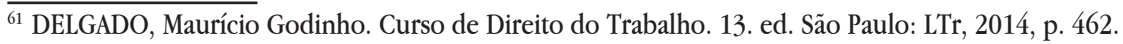

${ }^{62}$ Princípio da dignidade humana (art. $1^{\circ}$, III); valorização do trabalho e especialmente do emprego (art. $1^{\circ}$, III, c/c art. 170, caput); busca da construção de uma sociedade livre, justa e solidária (art. $3^{\circ}$, I); erradicação da pobreza e a marginalização e redução das desigualdades sociais (art. $3^{\circ}$, III); busca da promoção do bem de todos, sem preconceitos de origem, raça, sexo, cor, idade e quaisquer outras formas de discriminação (art. $3^{\circ}$, IV), todos da Constituição Federal de 1988.

${ }^{63}$ DELGADO, Maurício Godinho. Curso de Direito do Trabalho. 13. ed. São Paulo: Ltr, 2014, p. 462-463.
} 
Neste passo, constata-se que, desde a sua gênese, existe relação agonista entre a atividade empresarial e o direito do trabalho, que, por sua vez, se encontra inserida em uma ordem econômica mundial, caracterizada, de um lado, pela concorrência predatória entre seus principais agentes econômicos e, de outro, pela eclosão de crises globais cíclicas desagregadoras.

Com a inauguração do Estado democrático de Direito, o exercício da atividade empresarial restou vinculado ao cumprimento de sua função solidária, significando que a empresa tem o dever de contribuir, ao lado do Estado, com a constituição de uma sociedade livre, justa e solidária.

Nessa mesma linha, a empresa, por ser ambiente corolário da propriedade privada, está obrigada ao exercício de sua função social, devendo se conformar o exercício de sua atividade com as exigências do bem comum, sujeitando-se às obrigações que a limitem. Desse modo, as mudanças inerentes à produção de bens e serviços devem ser acompanhadas pelo processo de funcionalização da propriedade, haja vista que o exercício da função social da empresa é fundamento do regime jurídico do instituto da propriedade privada, de seu reconhecimento e da sua garantia, implicando o seu conteúdo.

Outrossim, apesar da necessidade imposta pela complexidade crescente do produto e pelas exigências do mercado, a atuação empresarial está atrelada à concretização dos direitos e garantias fundamentais sociais, significando que a segmentação das suas cadeias produtivas é limitada pelos princípios, regras e instituições trabalhistas previstos na ordem internacional em declarações e tratados, bem assim no âmbito nacional, na Constituição Federal brasileira e na legislação infraconstitucional.

É certo que não há como proibir a segmentação das cadeias produtivas, haja vista já fazer parte da realidade contemporânea, em que prevalece uma política capitalista globalizada, entretanto, esse processo de terceirização não pode ser realizado sem amarras.

Há, antes de tudo, que se delimitar a real necessidade técnica e econômica, ou análoga, para fragmentar um ciclo produtivo de bens e serviços. Sobretudo, no entanto, devem ser criados instrumentos que imponham limites à atividade empresarial terceirizada perante a precarização das relações de trabalho, tanto no plano jurídico - aplicando-se a responsabilidade solidária às empresas terceirizantes na contextura global - como no plano não jurídico - por exemplo, por meio de 
redes sindicais transnacionais.

Por último, invoca-se o princípio da vedação ao retrocesso social, basilar da Constituição Federal brasileira, que vislumbra a máxima eficácia das normas de direitos fundamentais, como óbice ao exercício da ação empresarial terceirizada em situações em que se configure a precarização dos direitos trabalhistas, devendo-se, portanto, estabelecer um patamar mínimo civilizatório para a atuação empresarial ante as relações de trabalho.

Conclui-se, então, que a atividade empresarial está estritamente vinculada ao cumprimento de sua função solidária e social, que, por sua vez, não se limita às restrições de uso e gozo que lhe são impostas. Mais do que isso, a empresa deve atuar efetivamente no sentido da promoção social e da concretização dos direitos fundamentais sociais.

\section{REFERÊNCIAS}

BERCOVICI, Gilberto. Constituição econômica e desenvolvimento: uma leitura a partir da Constituição de 1988. São Paulo: Malheiros, 2005.

BONAVIDES, Paulo. Curso de Direito Constitucional. 31. ed. São Paulo: Malheiros, 2016.

BRASIL. TST. RR - 1882-80.2010.5.02.0061. Data de Julgamento: 03/08/2016, Relator Ministro: Luiz Philippe Vieira de Mello Filho, $7^{a}$ Turma, Data de Publicação: DEJT 05/08/2016.

Disponível em: http://aplicaca05.tst.jus.br/consultaunificada2/inteiroTeor. do? action $=$ printInteiroTeor \&format $=\mathrm{html} \&$ highlight $=$ true\&numeroFormatado $=\mathrm{RR} \% 20$ $-\% 201882-80.2010 .5 \cdot 02.0061 \&$ base $=$ acordao\&rowid $=$ AAANGhAA + AAAO8aAAI\&dataP ublicacao $=05 / 08 / 2016 \&$ localPublicacao $=$ DEJT \&query $=\% 27$ efic\%E1cia\%20diagonal $\% 20$ dos\%20direitos\%20fundamentais\%27. Acesso em: 18 jun. 2017.

COMPARATO, Fábio Konder. Direito Empresarial: estudos e pareceres. São Paulo: Saraiva, 1995.

CONTRERAS, Sérgio Gamonal. Cidadania na empresa e eficácia diagonal dos direitos fundamentais. São Paulo: LTr, 2011. 
FABRE, Luiz (org.) Vade Mecum: Direito Internacional do Trabalho. São Paulo: Orgânica, 2013.

DELGADO, Maurício Godinho. Curso de Direito do Trabalho. 13. ed. São Paulo: Ltr, 2014.

DELGADO, Maurício Godinho; DELGADO, Gabriela Neves. Constituição da República e direitos fundamentais: dignidade da pessoa humana, justiça social e Direito do Trabalho. 2. ed. São Paulo: LTr, 2013.

GIDDENS, Anthony. Modernidade e identidade. Rio de Janeiro: Zahar, 2002.

GIDDENS, Anthony. Sociologia. Trad. de Alexandra Figueiredo et al. 6. ed. Lisboa: Fundação Calouste Gulbenkian, 2005.

GRAU, Eros Roberto. A ordem econômica na Constituição de 1988. 17. ed. São Paulo: Malheiros, 2015.

HARVEY, David. Condição pós-moderna. Tradução de Adail Ubirajara Sobral e Maria Stela Gonçalves. 25. ed. São Paulo: Loyola, 2014.

HOLMES, Stephen; SUNSTEIN, Cass R. El costo de los derechos: por qué la libertad depende de los impuestos. Trad. de Stella Mastrangelo. Buenos Aires: Siglo veintiuno, 2011.

LIMA, Francisco Meton Marques de. Elementos de Direito do Trabalho e processo do trabalho. 14. ed. São Paulo: LTr, 2013.

MAIOR, Jorge Luiz Souto. Relação entre o Processo Civil e o Processo do Trabalho. In: MIESSA, Elisson (org.). O novo Código de Processo Civil e seus reflexos no processo do trabalho. Salvador: Juspodvm, 2015.

MARMELSTEIN, George. Curso de direitos fundamentais. 5. ed. São Paulo: Atlas, 2014 .

MASLOW, Abraham H. Maslow no gerenciamento. Rio de Janeiro: Qualitymark, 2001. 
na Constituição Federal de 1988. Disponível em: http://www.periodicos.ufc.br/ nomos/article/view/6414. Acesso em: 23 jun. 2017.

MIRANDA, Fernando Hugo R. A questão das cadeias produtivas no âmbito do direito do trabalho e os limites da racionalidade da súmula n. 331/TST. Revista LTr, São Paulo: LTr, v. 80, n. 12, p. 1470-1481, dez./2016.

MIZIARA, Raphael; BRAGA, Roberto Wanderley. Informativos do TST: comentados e organizados por assunto. 2. ed. Salvador: JusPodivm, 2017.

NASCIMENTO, Marilza Geralda do. O trabalho como valor: afirmação e crise em perspectiva tridimensional. Dissertação de Mestrado. Faculdade de Direito. Universidade Federal de Minas Gerais, 2002.

PEREIRA, Caio Mário da Silva. Instituições de Direito Civil. Direitos reais. Atual. por MONTEIRO FILHO, Carlos Edison do Rêgo. 10. ed. Rio de Janeiro: Forense, 2005 , v. IV.

REQUIÃO, Rubens. A cogestão: a função social da empresa e o Estado de Direito. Revista Forense, São Paulo, a. 74, v. 262, pp. 31-39, abr.-jun./1978.

RODRIGUEZ, Américo Plá. Princípios de Direito do Trabalho. Trad. de Wagner D. Giglio. 3. ed. São Paulo: LTr, 2000.

SARLET, Ingo Wolfgang. Dignidade da pessoa humana e direitos fundamentais na Constituição Federal de 1988. 9. ed. Porto Alegre: Livraria do Advogado, 2012.

TEPEDINO, Gustavo. Temas de Direito Civil. 4. ed. Rio de Janeiro: Renovar, 2008.

TRINDADE, Antônio Augusto Cançado. Desafios e conquistas do direito internacional dos direitos humanos no início do século XXI. Disponível em: https://www.oas.org/dil/esp/407-490\%20cancado\%20trindade\%20OEA\%20CJI\%20 \%20.def.pdf. Acesso em: 30 jun. 2017.

VIANA, Márcio Túlio. A terceirização revisitada: algumas críticas e sugestões para um novo tratamento da matéria. Revista TST, v. 78, n. 4, pp. 198-224, out./dez., 2012.

VIANA, Márcio Túlio. As várias faces da terceirização. Revista Fac. Direito UFMG, 
Belo Horizonte, n. 54, pp. 141-156, jan./jun. 2009.

VIANA, Márcio Túlio. A proteção social do trabalhador no mundo globalizado: o direito do trabalho no limiar do século XXI. Revista Fac. Direito UFMG, Belo Horizonte, p. 153-186, 2000. Disponível em: https://www.direito.ufmg.br/revista/ index.php/revista/article/viewFile/1145/1078. Acesso em: 15 jul. 2017.

WEBER, Max. Economia e sociedade. Brasília: UnB, 2012, v. I.

Recebido em: 30/01/2018

Aceito em: 02/08/2019 